\title{
Association between Baseline Kidney Function and Change in CRP: An Analysis of the Cardiovascular Health Study
}

\author{
Dena E. Rifkin ${ }^{a}$ Ronit Katz ${ }^{b}$ Linda F. Fried ${ }^{\mathrm{e}}$ Bryan Kestenbaum $^{c}$ \\ Nancy Swords Jenny ${ }^{g}$ Anne B. Newman ${ }^{f}$ David S. Siscovick ${ }^{d}$ \\ Michael G. Shlipak ${ }^{\mathrm{h}}$ Mark J. Sarnak ${ }^{\mathrm{i}}$ \\ a Division of Nephrology, University of California, San Diego and Veterans' Affair Hospital, San Diego, Calif., \\ ${ }^{b}$ Collaborative Health Studies Coordinating Center, ' ${ }^{\mathrm{D}}$ Division of Nephrology, University of Washington, and \\ ${ }^{\mathrm{d}}$ Departments of Medicine and Epidemiology, Cardiovascular Health Research Unit, University of Washington, \\ Seattle, Wash., ' Veterans Affairs Pittsburgh Healthcare and Renal-Electrolyte Division, University of Pittsburgh \\ School of Medicine, and ${ }^{\mathrm{f} C e n t e r}$ for Aging and Population Health, Department of Epidemiology, University \\ of Pittsburgh School of Medicine, Pittsburgh, Pa., ${ }^{9}$ Department of Pathology, University of Vermont College \\ of Medicine, Burlington, Vt., ${ }^{\mathrm{h}}$ General Internal Medicine Section, Veterans Affairs Medical Center, and \\ the Departments of Medicine and Epidemiology and Biostatistics, University of California, San Francisco, \\ Calif., 'Division of Nephrology, Tufts Medical Center, Boston, Mass., USA
}

\section{Key Words}

Inflammation · Cystatin C · Kidney function • Epidemiology

\begin{abstract}
Background: In cross-sectional analyses, C-reactive protein (CRP) levels are inversely related to levels of kidney function. The relationship between kidney function and subsequent changes in CRP is unknown. Methods: We studied 4,364 individuals from the Cardiovascular Health Study, a longitudinal cohort of community-dwelling older adults. Baseline eGFRcys was estimated using cystatin C. CRP was measured at baseline and after 3 and 7 years of follow-up; slopes of change in CRP were calculated. Results: The mean (SD) age of the cohort was 72 (5.2) years; mean (SD) eGFRcys was $78.9(18.4) \mathrm{ml} / \mathrm{min} / 1.73 \mathrm{~m}^{2}$. The median (interquartile range IQR) baseline CRP was $2.39(1.22,4.33) \mathrm{mg} / \mathrm{l}$; the median (IQR)
\end{abstract}

yearly change in CRP was -0.0051 (-0.020 to 0.27$) \mathrm{mg} / \mathrm{l} / \mathrm{year}$. After adjustment for demographic characteristics and the initial level of CRP, each standard deviation lower baseline eGFR was associated with a small and non-significant yearly increase in CRP $(0.032 \mathrm{mg} / \mathrm{l} / \mathrm{year} ; 95 \% \mathrm{Cl}:-0.005$ to 0.070 , $p=0.094)$. Conclusions: We did not find a relationship between eGFR and subsequent changes in CRP. The association between kidney function and CRP in cross-sectional analyses may reflect unmeasured confounding by atherosclerosis; alternatively, the burden of comorbidity and interval mortality in this population may have masked a stronger longitudinal association between kidney function and change in CRP. Further study in younger populations may clarify whether impaired kidney function leads to change in inflammation over time.

Copyright $\odot 2010$ S. Karger AG, Basel

\section{KARGER}

(C) 2010 S. Karger AG, Basel

Fax +4161306 1234 E-Mail karger@karger.ch www.karger.com www.karger.com/nec
Dena E. Rifkin, MD, MS

9500 Gilman Drive

La Jolla, CA 92093-9111 (USA)

Tel. +1 858552 8585, ext. 2784, Fax +1 6176362369

E-Mail drifkin@ucsd.edu 


\section{Introduction}

Among patients with chronic kidney disease (CKD), cardiovascular mortality risk is markedly elevated. While cardiovascular morbidity and mortality are highest among those with kidney failure, there is increasing recognition that even mild decreases in glomerular filtration rate (GFR) are associated with increased risk of cardiovascular disease (CVD) [1-3]. The mediators for this association are not clear. While traditional CVD risk factors such as hypertension, diabetes and dyslipidemia are partially responsible for this relationship, non-traditional risk factors, such as inflammation, have also been associated with CVD in those with CKD $[1,4,5]$.

Levels of inflammatory markers have consistently been found to be elevated in patients with end-stage renal disease (ESRD) or kidney failure [6, 7]. Most $[8,9]$, but not all [10], studies have also suggested that the kidney function is associated with inflammatory markers in the earlier stages of kidney disease. In the Cardiovascular Health Study (CHS), the association between cystatin C, creatinine, and estimated GFR with C-reactive protein (CRP) has been examined in cross-sectional analyses; cystatin $\mathrm{C}$ was directly and linearly associated with levels of inflammatory markers, while creatinine and estimated GFR (eGFR) based on serum creatinine demonstrated U-shaped associations with CRP [1]. Most previous studies that have evaluated the relationship between level of kidney function and CRP have been cross-sectional [1, 9, 11]. To our knowledge no previous studies have evaluated the relationship between baseline kidney function and increasing levels of CRP in follow-up. There are reasons to suspect that kidney dysfunction may predate the development of inflammation. Potential mechanisms include decreased clearance of inflammatory cytokines $[12,13]$, greater insulin resistance and oxidative stress [14, 15] and aggravation of hypertension resulting in endothelial injury, all of which may lead to development or worsening of the inflammatory state.

We therefore evaluated the association between baseline kidney function, as ascertained by cystatin C-based estimations of GFR, and changes in CRP over up to 7 years of follow-up in a cohort of older adults.

\section{Methods}

\section{Study Population}

CHS is a longitudinal study of community-dwelling older adults designed to evaluate risk factors for CVD. The design of this study has been described previously [16]. In brief, participants 65 years of age or older were recruited from Medicare eligibility lists in 4 US communities (Forsyth County, N.C.; Sacramento County, Calif.; Washington County, Md.; Pittsburgh, Pa.). An initial 5,201 participants were recruited between 1989 and 1990. Blood samples were drawn in these individuals in 19891990 (year 0), 1992-1993 (year 3), and 1996-1997 (year 7). An additional 687 black participants were added to the study in 19921993; these individuals had blood samples drawn in 1992-1993 (year 3) and 1996-1997 (year 7).

All participants provided written informed consent, and the institutional review boards of the University of California San Francisco, University of Washington, and University of Pittsburgh approved the study.

\section{Measurement of Cystatin $C$ and CRP}

Frozen sera stored at $-70^{\circ} \mathrm{C}$ from the visits at year 0 (19891990), year 3 (1992-1993) and year 7 (1996-1997) were available for measurement of cystatin C and CRP. Cystatin C was measured using a particle-enhanced immunonephelometric assay [N Latex Cystatin C, Dade Behring (now Siemens), Deerfield, Ill., USA] with a nephelometer [BNII, Dade Behring (now Siemens)]. Previous work has shown cystatin $\mathrm{C}$ to be stable through several freezethaw cycles [17]. For cystatin C, the intra-assay and the inter-assay coefficients of variation ranged from 2.0 to $2.8 \%$ and from 2.3 to $3.1 \%$, respectively.

High-sensitivity CRP was measured at year 0 using an ELISA assay developed at the CHS reference laboratory [18]. This assay was subsequently calibrated to an automated commercial assay by repeating 500 samples and by matching CRP standards using both the old and new assays. Original values were standardized to follow up values using linear regression (adjusted baseline $\left.C R P=\mathrm{e}^{(\ln (\text { baseline CRP })+0.2781)}\right)$. Year 3 and 7 measures were performed using the automated assay on the BNII nephelometer from Dade Behring (N High Sensitivity CRP, Dade Behring Inc., Deerfield, Ill., USA). CRP has been demonstrated to be stable through several freeze-thaw cycles [18].

Predictor Variable: Estimated GFR Using Cystatin C

To estimate GFR using cystatin C (eGFRcys), we used an equation (eGFRcys $=76.7 \cdot \mathrm{cysC}^{-1.18}$ ) derived from a pooling of cohorts that used iothalamate clearance as the criterion standard [19]. Estimated GFR values $>130 \mathrm{ml} / \mathrm{min} / 1.73 \mathrm{~m}^{2}$ were truncated at 130 $\mathrm{ml} / \mathrm{min} / 1.73 \mathrm{~m}^{2}$, since values above these are unlikely to be accurate [3].

Outcome Variable: Change in C-Reactive Protein

Because of the non-normal distribution of CRP at each time point, in our initial analyses we transformed CRP levels by natural logarithms before calculating change. Because the findings were similar using the change in $\ln (\mathrm{CRP})$ versus change in CRP itself, we present the latter results for ease of interpretation. Change in CRP was calculated using the 2 or 3 measurements available for each individual. A least-squares regression slope was fitted to the available measurements and an annualized slope of change was calculated. We removed the small number of individuals with change $>10 \mathrm{mg} / \mathrm{l} /$ year from final models (45 individuals, or $<1 \%$ of the cohort), since these extreme changes were driven in each case by isolated CRP values $>70 \mathrm{mg} / \mathrm{l}$, and were likely to be due to acute inflammatory conditions that were bio- 


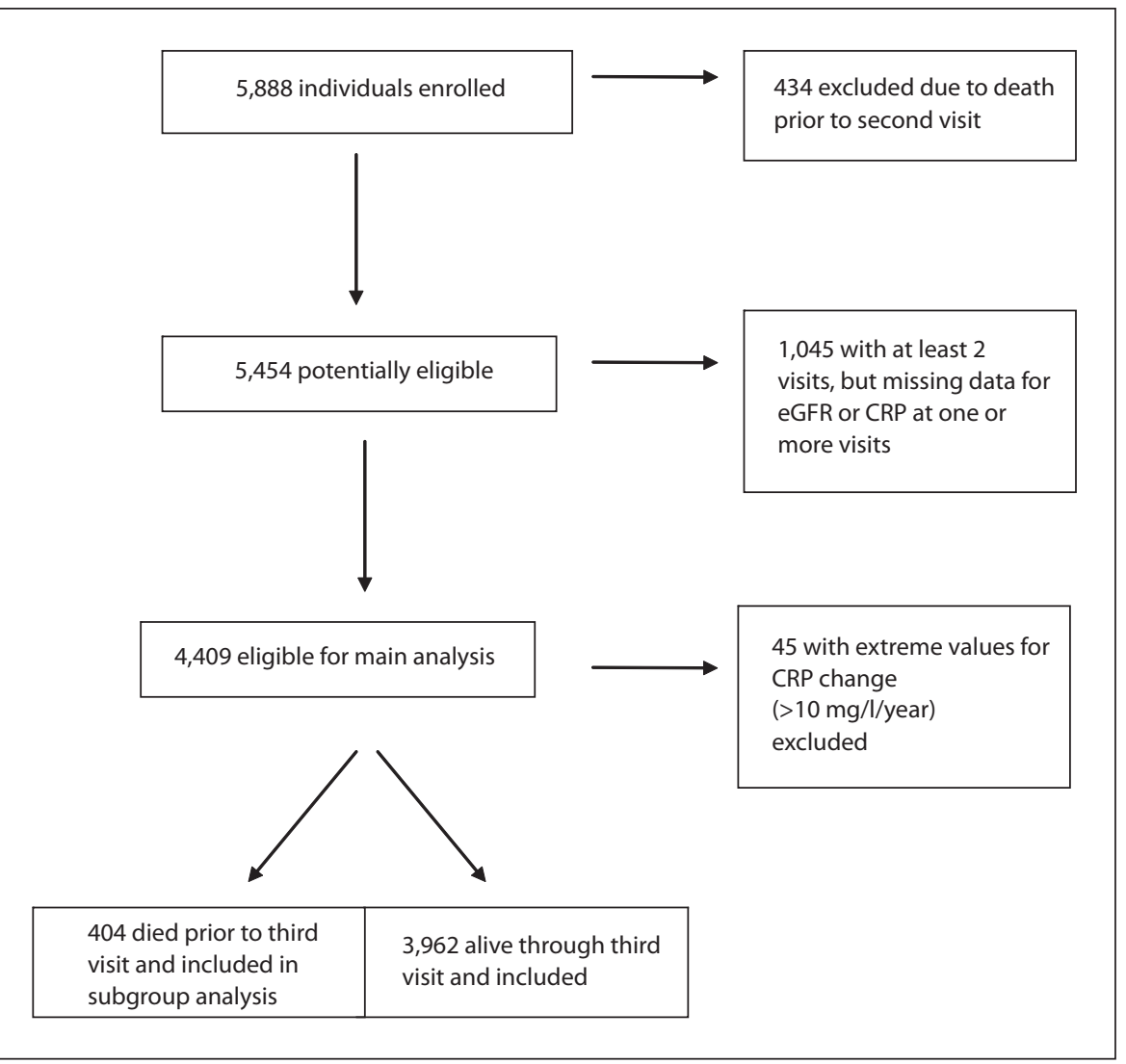

Fig. 1. Flow of participants through the study.

logically dissimilar to the conditions causing small changes in CRP. Given the difference in measurement technique for the year 0 versus year 3 and 7 CRP measurements, we performed a sensitivity analysis using only the year 3 and 7 values.

\section{Covariates}

Candidate covariates were chosen based on findings from prior studies of the cross-sectional association between eGFRcys and CRP or based on biological plausibility. Age, gender, and race were forced into adjusted models. The following baseline covariates were considered for inclusion: study variables (study site and recruitment cohort); cardiovascular risk factors (history of smoking, hypertension defined by use of antihypertensive agents, or an average of 3 blood pressure measurements $>140 / 90 \mathrm{~mm} \mathrm{Hg}$, diabetes defined by use of insulin or an oral hypoglycemic agent, or a fasting blood sugar $>6.99 \mathrm{mmol} / \mathrm{l}$, preexisting cardiovascular disease (previous stroke, coronary heart disease, or transient ischemic attack), subclinical vascular disease (ankle-arm index and carotid intima-media thickness), body mass index and medication use (including aspirin, calcium channel blockers, angiotensin-converting enzyme inhibitors, diuretics, beta-blockers, and 3-hydroxy-3-methyl-glutaryl-CoA reductase inhibitors).

\section{Analytic Methods}

We initially examined the relationship between eGFRcys and change in CRP on a continuous scale by creating scatter plots and then fitting cubic function plots to the data.
Covariates listed above were compared among participants across quintiles of baseline eGFRcys. The $\chi^{2}$ tests were used for discrete variables, and analysis of variance for continuous variables.

Linear regression was used to evaluate the association of eGFRcys with change in CRP initially without adjustment and subsequently after adjustment for demographic covariates and for baseline CRP. Interaction terms were considered in each model between baseline eGFRcys and baseline CRP after other covariates had been included; if the continuous interaction term was significant, then subgroup models for each level of baseline CRP (normal, <1 mg/l; intermediate, $1-3 \mathrm{mg} / \mathrm{l}$; high, $\geq 3 \mathrm{mg} / \mathrm{l}$ ) were performed. These cutoffs were defined in a American Heart Association/Centers for Disease Control and Prevention scientific statement [20] and have been extensively studied in the general population and in patients with cardiovascular disease [21, 22]. Variables were selected for inclusion in the final adjusted models based upon a combination of biological plausibility and whether or not they changed the coefficient of eGFRcys by 5 percent or more. The final models included age, race, gender, hypertension, diabetes, body mass index, and history of CVD, as well as cohort, diuretic use, and hemoglobin levels.

Two sensitivity analyses were performed. First, we performed subgroup analysis including only those individuals with a CRP less than the 'normal' cut-point of $1 \mathrm{mg} / \mathrm{l}$ at baseline in order to assess whether baseline kidney function was associated with slope of CRP in this subgroup. We theorized that if decreased kidney 
Table 1. Baseline characteristics by quintile of eGFRcys

\begin{tabular}{|c|c|c|c|c|c|c|}
\hline Quintiles of eGFRcys & $\begin{array}{l}\text { Quintile } 1 \\
104.8 \pm 9.3 \\
(\mathrm{n}=894)\end{array}$ & $\begin{array}{l}\text { Quintile } 2 \\
87.8 \pm 3.0 \\
(\mathrm{n}=848)\end{array}$ & $\begin{array}{l}\text { Quintile } 3 \\
79.0 \pm 15.5 \\
(n=870)\end{array}$ & $\begin{array}{l}\text { Quintile } 4 \\
69.6 \pm 3.0 \\
(\mathrm{n}=860)\end{array}$ & $\begin{array}{l}\text { Quintile } 5 \\
53.6 \pm 3.0 \\
(\mathrm{n}=892)\end{array}$ & $\begin{array}{l}\chi^{2} \text { or } \\
t \text { test } \\
p \text { value }\end{array}$ \\
\hline \multicolumn{7}{|l|}{ Demographics, \% } \\
\hline Age & $70.4 \pm 3.9$ & $71.3 \pm 4.5$ & $71.8 \pm 4.7$ & $72.7 \pm 5.2$ & $74.8 \pm 5.2$ & $<0.01$ \\
\hline Gender, female & 29.1 & 38.8 & 39.4 & 45.1 & 48.3 & $<0.01$ \\
\hline Race, white & 81.3 & 85.6 & 86.8 & 88.1 & 89.2 & $<0.01$ \\
\hline History of hypertension & 34.2 & 37.3 & 37.8 & 44.9 & 56.3 & $<0.01$ \\
\hline Smoking & 52.7 & 51.4 & 51.4 & 57 & 52.9 & 0.071 \\
\hline Diabetes & 14.1 & 11.6 & 13.5 & 13.5 & 17.2 & 0.017 \\
\hline Prevalent stroke & 1.3 & 2.2 & 2.1 & 4.1 & 7.2 & $<0.01$ \\
\hline Prevalent TIA & 1.0 & 1.2 & 3.6 & 2.1 & 4.5 & $<0.01$ \\
\hline Prevalent CHD & 12.9 & 13.1 & 16.8 & 20.9 & 27.0 & $<0.01$ \\
\hline \multicolumn{7}{|l|}{ Medication use, \% } \\
\hline Antihypertensive & 36.0 & 39.6 & 41.1 & 50.8 & 61.2 & $<0.01$ \\
\hline Statin & 3.1 & 3.0 & 2.0 & 2.3 & 2.4 & 0.503 \\
\hline Angiotensin-converting enzyme inhibitor & 5.2 & 5.7 & 5.3 & 8.0 & 10.6 & $<0.01$ \\
\hline Beta-blocker & 9.9 & 10.9 & 13.6 & 13.0 & 18.3 & $<0.01$ \\
\hline Diuretic & 17.6 & 22.5 & 21.5 & 29.1 & 42.9 & $<0.01$ \\
\hline Aspirin & 2.2 & 2.7 & 2.4 & 3.1 & 4.9 & 0.013 \\
\hline Calcium-channel blocker & 11.2 & 10.9 & 11.9 & 14.3 & 15.9 & $<0.01$ \\
\hline \multicolumn{7}{|l|}{ Laboratory and clinical assessments } \\
\hline Cystatin C, mg/l & $0.8 \pm 0.1$ & $0.9 \pm 0.03$ & $1.0 \pm 0.03$ & $1.1 \pm 0.04$ & $1.4 \pm 0.04$ & $<0.01$ \\
\hline Creatinine, $\mu \mathrm{mol} / \mathrm{l}$ & $53.4 \pm 15.3$ & $61.0 \pm 13.7$ & $68.6 \pm 15.3$ & $76.26 \pm 16.0$ & $91.5 \pm 16.0$ & $<0.01$ \\
\hline $\mathrm{eGFRcr}, \mathrm{ml} / \mathrm{min} / 1.73 \mathrm{~m}^{2}$ & $96.4 \pm 19.2$ & $85.8 \pm 16.3$ & $78.9 \pm 15.6$ & $72.6 \pm 15.1$ & $58.6 \pm 15.1$ & $<0.01$ \\
\hline Diastolic BP, mm Hg & $70.9 \pm 10.8$ & $70.8 \pm 10.4$ & $71.4 \pm 11.2$ & $70.5 \pm 11.3$ & $69.9 \pm 11.3$ & $<0.01$ \\
\hline Systolic BP, mm Hg & $133.7 \pm 20.7$ & $134.3 \pm 20.2$ & $134.6 \pm 21.3$ & $135.8 \pm 20.5$ & $138.0 \pm 20.5$ & $<0.01$ \\
\hline Baseline CRP, mg/l & $3.3 \pm 5.1$ & $3.7 \pm 5.9$ & $3.9 \pm 5.0$ & $4.2 \pm 5.9$ & $5.7 \pm 5.9$ & $<0.01$ \\
\hline Ankle-arm index & $1.1 \pm 0.1$ & $1.1 \pm 0.1$ & $1.1 \pm 0.2$ & $1.1 \pm 0.2$ & $1.0 \pm 0.2$ & $<0.01$ \\
\hline Hemoglobin, g/l & $139 \pm 15$ & $140 \pm 12$ & $141 \pm 13$ & $142 \pm 13$ & $139 \pm 13$ & $<0.01$ \\
\hline Albumin, $\mathrm{g} / \mathrm{l}$ & $40 \pm 3$ & $40 \pm 3$ & $40 \pm 3$ & $40 \pm 3$ & $40 \pm 3$ & $<0.01$ \\
\hline Fibrinogen, $\mu \mathrm{mol} / \mathrm{l}$ & $8.92 \pm 1.56$ & $9.03 \pm 1.71$ & $9.21 \pm 1.72$ & $9.46 \pm 1.88$ & $9.78 \pm 1.86$ & $<0.01$ \\
\hline Body mass index & $26.5 \pm 4.0$ & $26.4 \pm 4.6$ & $26.9 \pm 4.5$ & $27.1 \pm 4.7$ & $27.5 \pm 4.7$ & $<0.01$ \\
\hline Change in CRP, mg/l/year & $0.14 \pm 1.1$ & $0.13 \pm 1.3$ & $0.05 \pm 1.1$ & $0.08 \pm 1.3$ & $0.002 \pm 1.3$ & $<0.0$ \\
\hline
\end{tabular}

Data are given as mean \pm SD or as percentages. TIA $=$ Transient ischemic attack; CHD = coronary heart disease; eGFRcr $=$ estimated glomerular filtration rate based on serum creatinine.

function preceded increases in CRP, those increases would most likely be seen in the subgroup with normal initial CRP. Second, because of potential bias due to the competing risk of death, we examined the subgroup with measurements of CRP at baseline and year 3 but with mortality prior to year 7 . We hypothesized that this group would be sicker and therefore more likely to have an increased slope of CRP change. In all subgroup analyses, we adjusted for the same covariates found to be significant in the main analysis above. Analyses were performed using SAS (version 9.1, SAS Institute Inc., Cary, N.C., USA); $\mathrm{p} \leq 0.05$ were considered significant.

Kidney Function and Change in CRP

\section{Results}

Of the 5,888 individuals in the CHS cohort, 4,409 had more than one measure of CRP and a baseline measure of cystatin $\mathrm{C}$ and were therefore potentially eligible for this study. Figure 1 shows how subjects became eligible for inclusion in this study. The 1,479 individuals excluded based on absence of follow-up samples were older at the baseline visit (median age 75 vs. 72 years, $p<0.001$ ) and had more comorbid conditions ( 51 vs. $41 \%$ with a history of hypertension, 23 vs. $14 \%$ with diabetes); $25 \%$ of this 
Fig. 2. Distribution of slope of CRP.

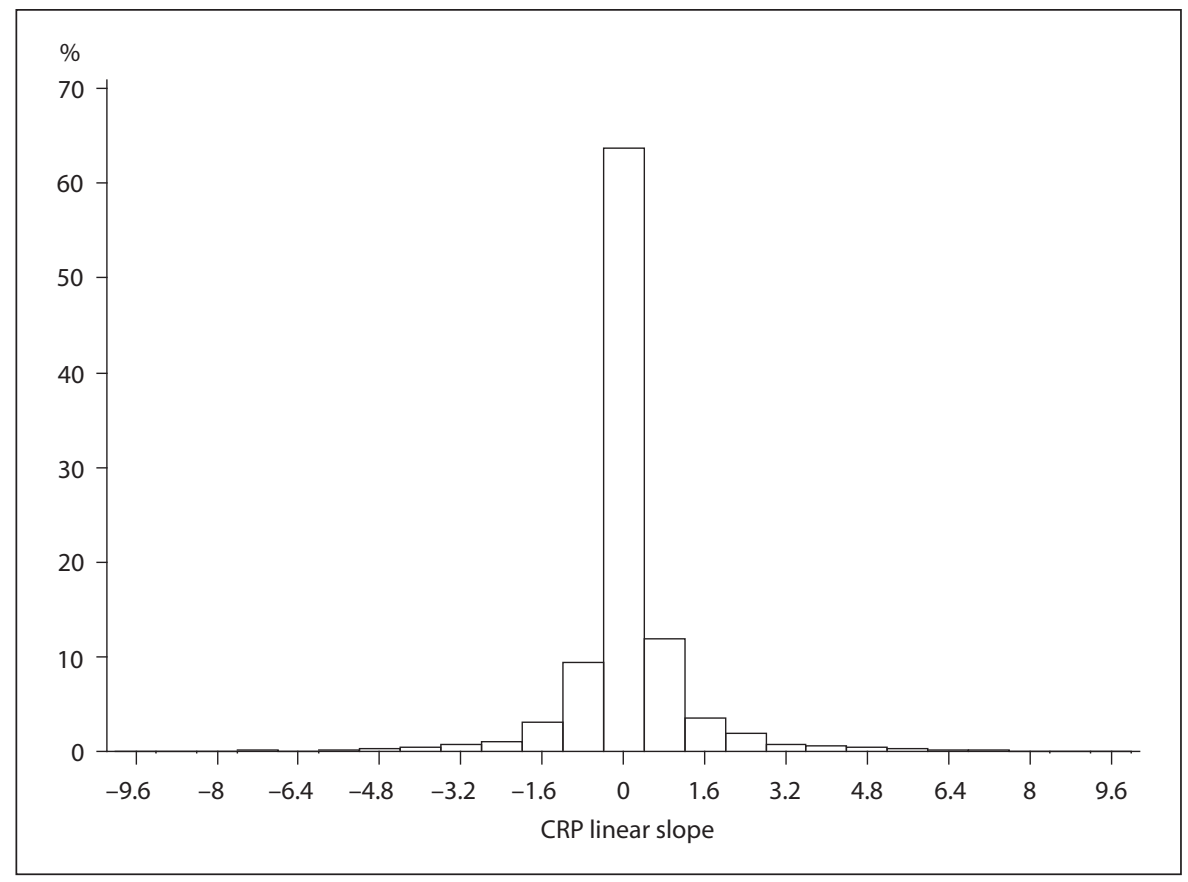

Fig. 3. Cubic function approximation of univariate relationship between GFR(cys) and CRP change (in $\mathrm{mg} / \mathrm{l} /$ year).

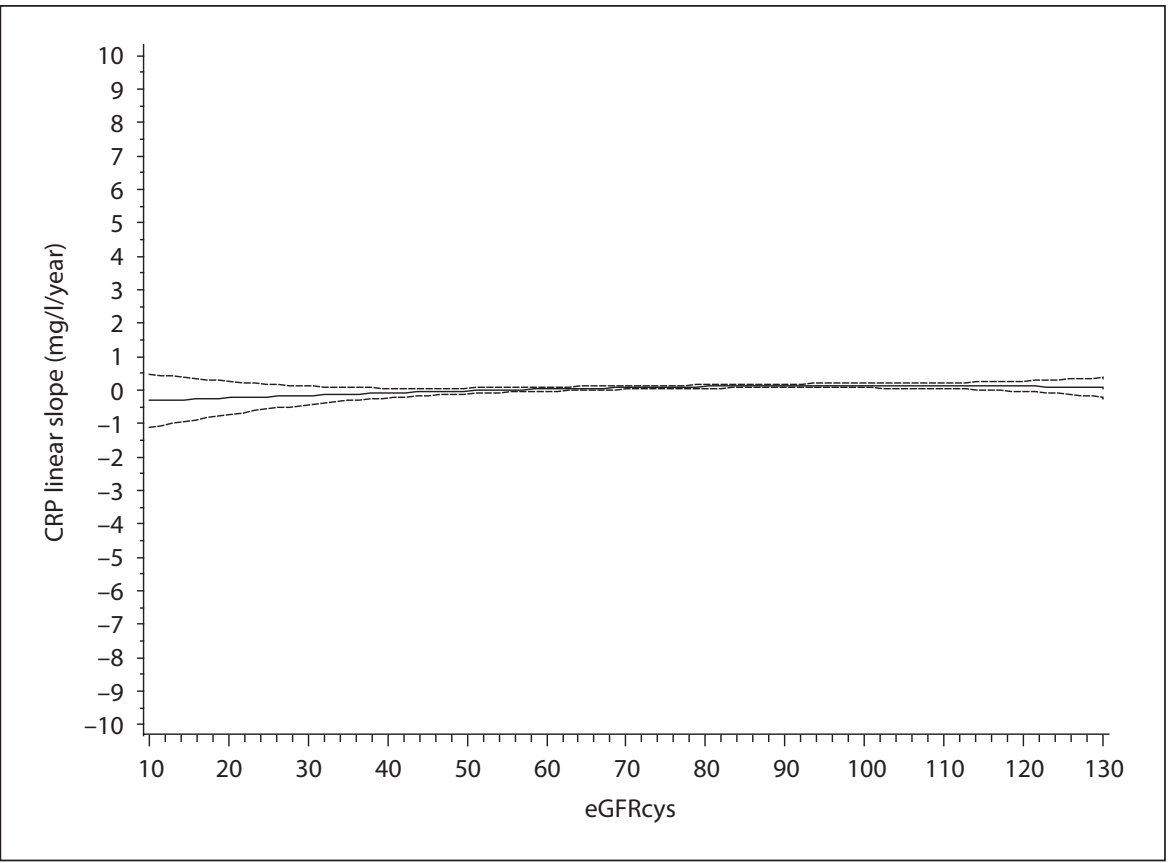

group died prior to the second clinic visit, and missing samples or loss to follow-up accounted for the remainder. As noted above, 45 additional individuals were excluded because of extreme CRP values, resulting in a yearly change $>10 \mathrm{mg} / \mathrm{l}$ of CRP.
Of the 4,364 participants included in the analysis, the median (interquartile range IQR) age at baseline was 71 (68-75) years; $14 \%$ had diabetes and $18 \%$ had prevalent cardiovascular disease. Those with lower eGFRcys were more likely to be female and white, had higher rates of hypertension and diabetes, and had higher baseline CRP 
Table 2. Univariate and multivariate models of linear CRP change, per standard deviation lower baseline GFR

\begin{tabular}{|c|c|c|c|}
\hline \multirow[t]{2}{*}{ Coefficient of eGFRcys } & \multicolumn{3}{|c|}{ CRP slope, $\mathrm{mg} / \mathrm{l} /$ year } \\
\hline & $\begin{array}{l}\text { yearly change } \\
\mathrm{mg} / \mathrm{l}\end{array}$ & $95 \% \mathrm{CI}$ & $\mathrm{p}$ value \\
\hline \multicolumn{4}{|c|}{ Full cohort, eGFRcys (per standard deviation lower) } \\
\hline Unadjusted & -0.052 & $-0.091,-0.013$ & 0.001 \\
\hline Adjusted $^{1}$ & -0.042 & $-0.085,0.0004$ & 0.052 \\
\hline Adjusted $^{2}$ & 0.032 & $-0.005,0.070$ & 0.094 \\
\hline \multicolumn{4}{|c|}{ Subgroup with initial CRP $<1 \mathrm{mg} / \mathrm{l}(\mathrm{n}=855)$} \\
\hline Unadjusted & 0.018 & $-0.04,0.07$ & 0.50 \\
\hline Adjusted $^{1}$ & 0.020 & $-0.04,0.073$ & 0.5 \\
\hline \multicolumn{4}{|c|}{ Subgroup with initial CRP $1-3 \mathrm{mg} / \mathrm{l}(\mathrm{n}=1,748)$} \\
\hline Unadjusted & 0.041 & $-0.0016,0.084$ & 0.06 \\
\hline Adjusted $^{1}$ & -0.043 & $-0.004,0.089$ & 0.07 \\
\hline \multicolumn{4}{|c|}{ Subgroup with initial CRP $>3 \mathrm{mg} / \mathrm{l}(\mathrm{n}=1,761)$} \\
\hline Unadjusted & -0.076 & $-0.155,0.003$ & 0.06 \\
\hline Adjusted $^{1}$ & -0.070 & $-0.158,0.018$ & 0.11 \\
\hline \multicolumn{4}{|c|}{ Subgroup with death prior to year $7(n=404)$} \\
\hline Unadjusted & -0.21 & $-0.38,-0.029$ & 0.02 \\
\hline Adjusted $^{1}$ & -0.24 & $-0.44,-0.05$ & 0.01 \\
\hline Adjusted $^{2}$ & -0.13 & $-0.31,0.047$ & 0.15 \\
\hline
\end{tabular}

${ }^{1}$ Adjusted for age, gender, race, hypertension, diabetes, body mass index, hemoglobin, diuretic use, prevalent CVD, and cohort.

${ }^{2}$ Adjusted for covariates in 1 and initial CRP.

(table 1). The Spearman correlation between eGFRcys and CRP was $-0.19(\mathrm{p}<0.001)$, whereas the Spearman correlation between GFRcys and yearly change in CRP was in the opposite direction [0.046 $(\mathrm{p}=0.003)]$.

The distribution of change in CRP is shown in figure 2 ; the median change in CRP was $-0.0051 \mathrm{mg} / \mathrm{l} /$ year with an IQR of -0.201 to 0.277 . In unadjusted continuous analysis using cubic function plots (fig. 3), there was no demonstrable association between baseline eGFRcys and change in CRP.

\section{Continuous Analysis}

The covariate-adjusted model showed each standard deviation lower baseline eGFR to be associated with small and non-significant decreases in CRP slope of -0.042 $\mathrm{mg} / \mathrm{l} /$ year $[95 \%$ confidence interval (CI): -0.085 to $-0.0004, p=0.05]$. After adjustment for baseline CRP, the direction of the association changed so that lower baseline eGFRcys was associated with small and non-significant increases in CRP over time of $0.032 \mathrm{mg} / \mathrm{l} /$ year $(95 \%$ CI: -0.005 to $0.070, \mathrm{p}=0.094$ ) (table 2 , model 1 vs. mod- el 2). This reversal of the association between eGFR and CRP slope was caused by the overall decline in CRP observed in those with high initial CRP (regression to the mean). The interaction between eGFRcys and baseline CRP was significant $(\mathrm{p}<0.001)$. We therefore performed a stratified analysis using the 3 traditional categories of initial CRP; however, no subgroup met criteria for significance (table 2).

\section{Sensitivity Analyses}

The results for the group with initial CRP $<1.0 \mathrm{mg} / \mathrm{l}$ and in the group with death prior to the seventh year of follow-up are shown in table 2. In neither subgroup was the baseline eGFRcys significantly associated with the change in CRP in adjusted analysis. Excluding the year 0, measures of CRP did not significantly alter the results.

\section{Discussion}

In summary, we noted a small and non-significant association between baseline eGFRcys and an increase in CRP over the course of 7 years of follow-up. This finding was influenced by the baseline CRP, and in all subgroups the relation between eGFRcys and subsequent CRP change was non-significant.

To our knowledge, the current study is the first to examine the effects of baseline kidney function on changes in CRP over a long period of time. In multiple other studies, a cross-sectional relationship between eGFR and CRP has been noted. Since in other studies [23, 24] higher baseline CRP was not associated with decreases in GFR in follow-up, we hypothesized that the reverse might be true. At least in this older community-dwelling cohort, however, the effect of baseline GFR on changes in CRP was, even at the extremes of the confidence intervals, a modest one.

There are several possibilities for the non-significant relation we noted between kidney function and increase in CRP. First, relationships previously noted in cross-sectional analysis may not reflect causality, and external factors such as the burden of atherosclerotic disease may promote both decreased eGFRcys and increased CRP. Second, in this community-dwelling older population, the changes in CRP over the course of 7 years could have been too small for an association to be detected; indeed, in this study, the change in CRP was centered around zero. The changes in CRP that did occur in this cohort may have been a reflection of random variation rather than meaningful change in the inflammatory state of the 
participant. A pattern of small, random variation is consistent with one previous study over a course of 6 months, which showed a small index of individuality and relatively minimal short-term fluctuations [18]; however, that short study was in normal volunteers, a population in whom stability would be expected, whereas our study was in older adults in whom chronic illness is more common. Alternatively, if a low eGFRcys causes an inflammatory response (increase in CRP) very quickly (e.g. over days or weeks), longitudinal data such as this would not show a relationship between baseline eGFR and subsequent increases in CRP years later. In fact, if this were true, the cross-sectional relationship would be a better proxy for the relationship between the 2 variables. Fourth, because of informative censoring due to death we may have missed a stronger relationship. This seems less likely, as the subgroup with 2 measurements of CRP prior to death also did not demonstrate a relation between baseline eGFRcys and change in CRP.

There are several limitations to this analysis. We did not have a gold standard measure of kidney function but instead relied on estimates from cystatin C. However, cystatin $\mathrm{C}$ is correlated with CRP at baseline, and so a relationship with CRP over time was plausible. We used a newly developed equation to estimate GFR using cystatin C; while several different equations have been proposed for eGFRcys, this equation is based on the largest cohort of subjects derived from multiple data sources that all used nephelometric methods to measure cystatin C [19]. We are unable to evaluate CRP in those who did not survive to have multiple measures; these older and sicker individuals had worse baseline kidney function and thus may have been those most likely to have increasing CRP over time. This introduces a potential for survivor bias; i.e. the subgroup available for study may be less likely to experience change in CRP. However, we did examine the group included in the study but who died prior to the last study visit; the same relationships were seen in this sicker subgroup.

In conclusion, we did not detect an association between estimated GFR using cystatin $C$ and changes in CRP in follow-up. Future studies should examine other potential causes or links between decreased kidney function and inflammation, including other markers of atherosclerosis.

\section{Acknowledgements}

The research reported in this article was supported by contract numbers R01-AG-027002, N01-HC-85079 through N01-HC85086, N01-HC-35129, N01 HC-15103, N01 HC-55222, N01-HC75150, N01-HC-45133, grant number U01 HL080295 from the National Heart, Lung, and Blood Institute, with additional contribution from the National Institute of Neurological Disorders and Stroke. A full list of principal CHS investigators and institutions can be found at http://www.chs-nhlbi.org/pi.html.

\section{References}

1 Shlipak MG, Fried LF, Cushman M, Manolio TA, Peterson D, Stehman-Breen C, Bleyer A, Newman A, Siscovick D, Psaty B: Cardiovascular mortality risk in chronic kidney disease: comparison of traditional and novel risk factors. JAMA 2005;293:1737-1745.

-2 Foley RN, Parfrey PS, Sarnak MJ: Clinical epidemiology of cardiovascular disease in chronic renal disease. Am J Kidney Dis 1998; 32:S112-S119.

-3 Manjunath G, Tighiouart H, Coresh J, Macleod B, Salem DN, Griffith JL, Levey AS, Sarnak MJ: Level of kidney function as a risk factor for cardiovascular outcomes in the elderly. Kidney Int 2003;63:1121-1129.

4 Muntner P, Hamm LL, Kusek JW, Chen J, Whelton PK, He J: The prevalence of nontraditional risk factors for coronary heart disease in patients with chronic kidney disease. Ann Intern Med 2004;140:9-17.
5 Muntner P, He J, Astor BC, Folsom AR, Coresh J: Traditional and nontraditional risk factors predict coronary heart disease in chronic kidney disease: results from the atherosclerosis risk in communities study. J Am Soc Nephrol 2005; 16:529-538.

6 6 Yeun JY, Levine RA, Mantadilok V, Kaysen GA: C-Reactive protein predicts all-cause and cardiovascular mortality in hemodialysis patients. Am J Kidney Dis 2000;35:469476.

7 Wanner C, Zimmermann J, Schwedler S, Metzger T: Inflammation and cardiovascular risk in dialysis patients. Kidney Int Suppl 2002;80:99-102.

-8 Shlipak MG, Fried LF, Crump C, Bleyer AJ, Manolio TA, Tracy RP, Furberg CD, Psaty BM: Elevations of inflammatory and procoagulant biomarkers in elderly persons with renal insufficiency. Circulation 2003;107: $87-92$.
-9 Stuveling EM, Hillege HL, Bakker SJ, Gans RO, De Jong PE, De Zeeuw D: C-reactive protein is associated with renal function abnormalities in a non-diabetic population. Kidney Int 2003;63:654-661.

10 Menon V, Wang X, Greene T, Beck GJ, Kusek JW, Marcovina SM, Levey AS, Sarnak MJ: Relationship between C-reactive protein, albumin, and cardiovascular disease in patients with chronic kidney disease. Am J Kidney Dis 2003;42:44-52.

11 Uhlig K, Sarnak MJ, Singh AK: New approaches to the treatment of calcium and phosphorus abnormalities in patients on hemodialysis. Curr Opin Nephrol Hypertens 2001;10:793-798.

12 Pecoits-Filho R, Heimburger O, Barany P, Suliman M, Fehrman-Ekholm I, Lindholm B, Stenvinkel P: Associations between circulating inflammatory markers and residual renal function in CRF patients. Am J Kidney Dis 2003;41:1212-1218. 
13 Pereira BJ, Shapiro L, King AJ, Falagas ME, Strom JA, Dinarello CA: Plasma levels of IL1 beta, TNF alpha and their specific inhibitors in undialyzed chronic renal failure, CAPD and hemodialysis patients. Kidney Int 1994;45:890-896.

14 Kubo M, Kiyohara Y, Kato I, Iwamoto H, Nakayama K, Hirakata H, Fujishima M: Effect of hyperinsulinemia on renal function in a general Japanese population: the Hisayama study. Kidney Int 1999;55:2450-2456.

- 15 Fliser D, Pacini G, Engelleiter R, KautzkyWiller A, Prager R, Franek E, Ritz E: Insulin resistance and hyperinsulinemia are already present in patients with incipient renal disease. Kidney Int 1998;53:1343-1347.

-16 Fried LP, Borhani NO, Enright P, Furberg CD, Gardin JM, Kronmal RA, Kuller LH, Manolio TA, Mittelmark MB, Newman A, et al: The Cardiovascular Health Study: design and rationale. Ann Epidemiol 1991;1:263-276.

- 17 Finney H, Newman DJ, Gruber W, Merle P, Price CP: Initial evaluation of cystatin C measurement by particle-enhanced immunonephelometry on the Behring nephelometer systems (BNA, BN II). Clin Chem 1997; 43:1016-1022.
8 Macy EM, Hayes TE, Tracy RP: Variability in the measurement of C-reactive protein in healthy subjects: implications for reference intervals and epidemiological applications. Clin Chem 1997;43:52-58.

19 Stevens L, Coresh J, Schmid CH, Feldman HI, Froissart M, Kusek J, Rossert J, Van Lente F, Bruce RD, Zhang Y, Greene T, Levey AS Estimating GFR using serum cystatin C alone and in combination with serum creatinine: a pooled analysis of 3,418 individuals with CKD. Am J Kidney Dis 2008;51: 395-406.

20 Pearson TA MG, Alexander RW, Anderson JL, Cannon RO, III, Criqui M, et al: Marker of inflammation and cardiovascular disease: application to clinical and public health practice: a statement for healthcare professionals from the Centers for Disease Control and Prevention and the American Heart Association. Circulation 2003; 107: 499-511.
21 Ridker PM: High-sensitivity C-reactive protein and cardiovascular risk: rationale for screening and primary prevention. Am J Cardiol 2003;92:17K-22K.

-22 Sabatine MS, Morrow DA, Jablonski KA, Rice MM, Warnica JW, Domanski MJ, Hsia J, Gersh BJ, Rifai N, Ridker PM, Pfeffer MA, Braunwald E: Prognostic significance of the Centers for Disease Control/American Heart Association high-sensitivity C-reactive protein cut points for cardiovascular and other outcomes in patients with stable coronary artery disease. Circulation 2007;115:15281536.

23 Sarnak MJ, Poindexter A, Wang SR, Beck GJ, Kusek JW, Marcovina SM, Greene T, Levey AS: Serum C-reactive protein and leptin as predictors of kidney disease progression in the Modification of Diet in Renal Disease Study. Kidney Int 2002;62:2208-2215.

24 Menon V, Greene T, Wang X, Pereira AA, Marcovina SM, Beck GJ, Kusek JW, Collins AJ, Levey AS, Sarnak MJ: C-reactive protein and albumin as predictors of all-cause and cardiovascular mortality in chronic kidney disease. Kidney Int 2005;68:766-772. 